\title{
Ectopic pregnancy: one-year retrospective study on clinical, investigational and operative correlation in a tertiary care hospital
}

\section{Basant Kumar Pati*}

Department of Obstetrics and Gynecology, Institute of Medical Sciences and SUM Hospital, Bhubaneswar, Odisha, India

Received: 30 September 2017

Accepted: 30 October 2017

*Correspondence:

Dr. Basant Kumar Pati,

E-mail: drkitusraban@gmail.co

Copyright: ( $)$ the author(s), publisher and licensee Medip Academy. This is an open-access article distributed under the terms of the Creative Commons Attribution Non-Commercial License, which permits unrestricted non-commercial use, distribution, and reproduction in any medium, provided the original work is properly cited.

\begin{abstract}
Background: Ectopic pregnancy is a life-threatening emergency which is one of the important cause of maternal mortality. Ectopic pregnancy must be suspected in any woman in the reproductive age group, presenting with lower abdominal pain or vaginal bleeding. Our aim was to review all cases of ectopic pregnancy and determine the incidence, high risk factors, types of clinical presentation and mode of management.

Methods: This was a retrospective cohort study, conducted at a tertiary care hospital. Medical records of all women with an ectopic pregnancy between 2016 and 2017 were seen. Demographic data, risk factors, clinical features, and mode of management were noted.

Results: 90 patients, diagnosed with ectopic pregnancy during last one year was included in the present study, with an incidence of $1.2 \%$. Majority of women were aged $20-30$ years (50\%). 74.4\% cases were ruptured ectopic. The most common risk factors were previous ectopic (50\%) and pelvic inflammatory disease $(17.7 \%)$. Lower abdominal pain was seen in $80(40.3 \%)$ patients. Majority of patients $(91.1 \%)$ had tubal ectopic pregnancies. Most common mode of treatment was salpingectomy.

Conclusions: Risk factors for ectopic pregnancy must be enquired and early diagnosis and management to be done to avoid maternal morbidity and mortality.
\end{abstract}

Keywords: Ectopic, Pregnancy, Salpingectomy, Ultrasonography

\section{INTRODUCTION}

An ectopic pregnancy is diagnosed when a fertilized ovum implants outside the normal uterine cavity. It is the most important cause of maternal mortality and morbidity in the first trimester of pregnancy. ${ }^{1}$ In developing countries like India, incidence of ectopic pregnancy is around $1 \%-3 \%$, which is much higher than those reported in developed countries. ${ }^{2}$ Number of cases of ectopic pregnancy is also rising due to increase in vitro fertilization. Increased awareness of ectopic pregnancy and a knowledge of the associated risk factors is helpful in identifying women at higher risk in order to facilitate early diagnosis. Most common risk factors are damage to the fallopian tube during previous pelvic or abdominal surgery or infection. Chlamydia trachomatis has been linked to $30-50 \%$ of all ectopic pregnancy. ${ }^{3}$ Patients with an ectopic pregnancy commonly present with pain and vaginal bleeding between 6 and 10 weeks of pregnancy. ${ }^{4}$ The diagnosis of ectopic pregnancy has become more frequent during the last decades. Incidence of ectopic pregnancy rupture has declined due to early diagnosis by quantitative hCG measurements and trans vaginal ultrasonography. ${ }^{5}$ Early diagnosis reduces the risk of tubal rupture and allows more conservative medical management. This retrospective study was done to 
determine the incidence, clinical features, risk factors, and treatment of ectopic pregnancy in a tertiary care hospital.

\section{METHODS}

90 patients of ectopic pregnancy admitted to a tertiary care hospital in Odisha, over a period of one year from January 2016 to January 2017 were included. The age, parity and presenting symptoms were recorded. History of prior surgery, tubal surgery, infertility, pelvic inflammatory disease and previous ectopic was taken. Vital parameters were recorded, and a thorough abdominal and bimanual examination was done. The diagnosis was made with the help of urine pregnancy test and ultrasonography. The abdominal findings after exploration were recorded. Treatment given was recorded as medical or surgical. Data was entered in Microsoft Excel spreadsheet and analyzed using SPSS software version 19.0. For categorical variables, data was compiled as frequency and percentage. For continuous variables, data was calculated as mean $\pm \mathrm{SD}$.

\section{RESULTS}

In the present study conducted over a period of one year, the total number of deliveries was 4550 . The total number of ectopic pregnancies were 90 . The incidence of ectopic pregnancy was 19 per 1000 live births. In the present study, we found that the majority of ectopic pregnancies, that is $45(50 \%)$, occurred in the females of the age group $20-30$ years. $22(24.4 \%)$ patients were in age group of 30 40 years. $15(16.6 \%)$ patients were in age group of less than 20 years (Table 1). 67 patients $(74.4 \%)$ were ruptured ectopic and $23(25.5 \%)$ patients were unruptured ectopic.

Table 1: Age wise distribution of ectopic pregnancy cases.

\begin{tabular}{|l|l|}
\hline Age group & Number of patients, $n=90(\%)$ \\
\hline$<20$ & $15(16.6 \%)$ \\
\hline $20-30$ & $45(50 \%)$ \\
\hline $30-40$ & $22(24.4)$ \\
\hline$>40$ & $8(8.8 \%)$ \\
\hline
\end{tabular}

$11(12.2 \%)$ patients were multiparus and $10(11.1 \%)$ patients were nulliparus of all ectopic pregnancies in the present study as shown in Table 2 .

Table 2: Parity in the present study.

\begin{tabular}{|ll|}
\hline Parity & Number of patients, $n=90(\%)$ \\
\hline 0 & $10(11.1 \%)$ \\
\hline 1 & $42(46.6 \%)$ \\
2 & $27(30 \%)$ \\
\hline 3 and above & $11(12.2 \%)$ \\
\hline
\end{tabular}

Table 3 shows that most of the patient had risk factors. The most common was history of previous ectopic in 30 patients $(33.3 \%)$ followed by pelvic inflammatory disease in $16(17.7 \%)$ patients. History of previous abortion and history of previous pelvic surgery was in 15 (16.6\%) patients each.

Table 3: Risk factors for ectopic pregnancy.

\begin{tabular}{|l|l|}
\hline Risk factors & $\begin{array}{l}\text { Number of } \\
\text { patients } n=90(\%)\end{array}$ \\
\hline $\begin{array}{l}\text { History of pelvic inflammatory } \\
\text { disease }\end{array}$ & $16(17.7 \%)$ \\
\hline History of tubal ligation & $10(11 \%)$ \\
\hline $\begin{array}{l}\text { History of previous pelvic } \\
\text { surgery }\end{array}$ & $15(16.6 \%)$ \\
\hline History of previous ectopic & $30(33.3 \%)$ \\
\hline History of previous abortion & $15(16.6)$ \\
\hline History of infertility & $2(2.2 \%)$ \\
\hline No identifiable risk factors & $2(2.2 \%)$ \\
\hline
\end{tabular}

Most of the patients presented with lower abdominal pain (88\%), followed by abnormal uterine bleeding (87\%), and amenorrhea (84\%). $75 \%$ had abdominal guarding and rigidity. $38 \%$ had both cervical motion tenderness and adnexal mass each. $20 \%$ patients presented with syncope (Table 4).

Table 4: Clinical presentation.

\begin{tabular}{|l|l|}
\hline Clinical features & $\begin{array}{l}\text { Number of } \\
\text { patients n=90 (\%) }\end{array}$ \\
\hline Lower abdominal pain & $80(88 \%)$ \\
\hline Cervical motion tenderness & $35(38 \%)$ \\
\hline Amenorrhea & $76(84 \%)$ \\
\hline Abnormal uterine bleeding & $79(87 \%)$ \\
\hline Abdominal guarding and rigidity & $68(75 \%)$ \\
\hline Adnexal mass or fullness & $35(38 \%)$ \\
\hline Syncope & $18(20 \%)$ \\
\hline
\end{tabular}

Table 5 shows site of ectopic pregnancy. Most common site was fallopian tube in $82(91.1 \%)$ patients.6 (6.6\%) patients had tubo ovarian pregnancy and 2 (2.2\%) patients had broad ligament pregnancy.

Table 5: Site of ectopic pregnancy.

\begin{tabular}{|ll|}
\hline Site & No of patients, $n=90(\%)$ \\
\hline Tubal & $82(91.1 \%)$ \\
\hline Tubo ovarian & $6(6.6 \%)$ \\
\hline Broad ligament & $2(2.2 \%)$ \\
\hline
\end{tabular}

Table 6: Modalities of management in present study.

\begin{tabular}{|ll|}
\hline Management & No. of patients, $\mathrm{n}=90(\%)$ \\
\hline Salpingectomy & $74(82.4 \%)$ \\
\hline Salpingo-oophorectomy & $6(6.4 \%)$ \\
\hline Medical management & $10(11.1 \%)$ \\
\hline
\end{tabular}

In the present study, surgery in the form of salpingectomy was done in $74(82.4 \%)$ patients. Salpingo- 
oophorectomy was done in 6 (6.4\%) patients. Salpingectomy or salpingo-oophorectomy was done either by open method or laparoscopically. Medical management with methotrexate was given to ten patients (11.1\%) (Table 6).

\section{DISCUSSION}

Ectopic pregnancy related maternal mortality in India is $3.5-7.1 \% .^{6}$ The incidence of ectopic pregnancy found in the present study was $1.9 \%$. Higher incidence was reported by authors like Ayaz A et al $(0.58 \%)$, by Bangash and Ahmad et al $(1.04 \%)$ and by Waseem et al( $1 \%) .{ }^{7-9}$ Lozeau et al reported incidence of ectopic pregnancy as $1.9 \%$ in USA which is similar to ours. ${ }^{10}$ The incidence of ectopic pregnancy was found to be highest in 20-30 year age group. This is due to the fact that it is the reproductive age group and has higher risk of sexual behavior.

History of previous ectopic, pelvic inflammatory disease, abortion and history of tubal surgery, tubal ligation was found to be the most common risk factors associated with ectopic pregnancy in present study. The increased risk in developed countries has been attributed to pelvic inflammatory disease, smoking and increased use of assisted reproductive technology. Successful management of ectopic pregnancy depends on earlier diagnosis and management. It decreases the morbidity, mortality and hospital stay. ${ }^{11} \mathrm{~A}$ high index of suspicion is required for earlier diagnosis. Lower abdominal pain and uterine bleed are the commonest presenting features in the present study.

In the present study, majority of patients had ruptured ectopic pregnancy which was diagnosed by ultrasonography. Commonest site of ectopic pregnancy in present study was fallopian tube which has also been reported by other studies. ${ }^{11,12}$ Immediate resuscitation with intravenous fluids, blood and emergency laparotomy and salpingectomy is required in cases of acute presentation with ruptured ectopic pregnancy. ${ }^{12}$ Since most cases in present study were ruptured ectopic pregnancy, salpingectomy was the commonest life-saving surgical procedure performed. A large number of patients required blood transfusion intraoperatively and postoperatively. This was due to delayed hospitalization and diagnosis. There was no death due to ectopic pregnancy in the present study. Maternal mortality due to ectopic pregnancy was reported to be between $0 \%-1.3 \%$ in other studies. ${ }^{12}$

Mortality is mostly due to hemorrhage following rupture of the ectopic pregnancy which was again due to delayed referrals and diagnosis. In UK, National Institute for Health and Clinical Excellence has estimated that twothirds of maternal deaths due to ectopic pregnancies was associated with inadequate care. Prevention and treatment of pelvic inflammatory disease and encouraging women to undergo an early transvaginal ultrasonography is required to prevent late diagnosis. Setting up Early Pregnancy Assessment Units (EPAU) has not only resulted in higher quality and cost-effective care but also have a positive effect on early pregnancy care in the $\mathrm{UK}{ }^{13}$

\section{CONCLUSION}

In developing countries like India, ectopic pregnancy is a common gynaecological emergency and remains a challenge. Ectopic pregnancy must be kept in mind if a woman presents with lower abdominal pain. Setting Early Pregnancy Assessment Units (EPAU) along with public health awareness is the key in diagnosing ectopic pregnancy early, thereby reducing the mortality particularly in developing countries like India.

Funding: No funding sources

Conflict of interest: None declared

Ethical approval: The study was approved by the Institutional Ethics Committee

\section{REFERENCES}

1. Singh S, Mahendra G, Vijayalakshmi S, Pukale RS. Clinical study of ectopic pregnancy in a rural setup: a two year survey. Natl J Med Res. 2014;4(1):37-9.

2. Igwegbe A, Eleje G, Okpala B. An Appraisal of the management of ectopic pregnancy in a Nigerian Tertiary Hospital. Ann Med Health Sci Res. 2013;3(2):166-70.

3. Sisti G, Kanninen TT, Di TM, Witkin SS, Spandorfer SD. Autophagy induction by sera from women undergoing an in vitro fertilization cycle varies with subsequent outcome. J Reprod Immunol. 2016;117:1-3.

4. Lin S, Yang R, Chi H, Lian Y, Wang J, Huang S. Increased incidence of ectopic pregnancy after in vitro fertilization in women with decreased ovarian reserve. Oncotarget. 2017;28:14570-5.

5. Ramer I, Kanninen TT, Sisti G, Witkin SS, Spandorfer SD. The serum brain-derived neurotrophic factor concentration prior to initiation of an in vitro fertilization cycle predicts outcome. $\mathbf{J}$ Reprod Immunol. 2016;116:46-9.

6. Ayaz A, Emam S, Farooq MM. Cliical course of ectopic pregnancy: a single center experience. J Hum Reprod Sci. 2013;6:70-3.

7. Bangash N, Ahmad H. A study of 65 cases of ectopic pregnancy in one-year period in military hospital. Pak Armed Forces Med J. 2004;54:205-8.

8. Waseem T. Proportionate morbidity and risk factors of ectopic pregnancy. Ann King Edward Med Univ. 2004;10:298-300.

9. Lozeau AM, Potter B. Diagnosis and management of ectopic pregnancy. Am Fam Physcian. 2005;72:1707-14.

10. Sivalingam VN, Duncan WC, Kirk E, Shephard LA, Horne AW. Diagnosis and management of ectopic 
pregnancy. J Fam Plann Reprod Health Care. 2011;37:231-40.

11. Practice Committee of the American Society of Reproductive Medicine. Medical treatment of ectopic pregnancy. Fertil Steril. 2008;90(5):S206-12.

12. Sotubo O, Aboyeji AP. Ectopic pregnancy in Ilorin, Nigeria: a five-year review. Niger Med Pract. 1994;27:25-7.
13. Ectopic pregnancy and miscarriage. NICE Quality standard. National Institute for Health and Clinical Excellence; 2014.

Cite this article as: Pati BK. Ectopic pregnancy: one-year retrospective study on clinical, investigational and operative correlation in a tertiary care hospital. Int J Reprod Contracept Obstet Gynecol 2017;6:5519-22. 